Reproduced from The Journal of Experimental Medicine, 1944, vol. 79, pp. 137-158

by copyright permission of The Rockefeller University Press

\title{
STUDIES ON THE CHEMICAL NATURE OF THE SUBSTANCE INDUCING TRANSFORMATION OF PNEUMOCOCCAL TYPES
}

\author{
Induction of Transformation by a Desoxyribondcleic Acid Fraction \\ IsOlated From PNEUMOCOCCUS TyPe III
}

\author{
By OSWALD T. AVERY, M.D., COLIN M. MACLEOD, M.D., AND \\ MACLYN MCCARTY,* M.D. \\ (From the Hospital of The Rockefeller Institute for Medical Research) \\ Plate 1 \\ (Received for publication, November 1, 1943)
}

Biologists have long attempted by chemical means to induce in higher organisms predictable and specific changes which thereafter could be transmitted in series as hereditary characters. Among microörganisms the most striking example of inheritable and specific alterations in cell structure and function that can be experimentally induced and are reproducible under well defined and adequately controlled conditions is the transformation of specific types of Pneumococcus. This phenomenon was first described by Griffith (1) who succeeded in transforming an attenuated and non-encapsulated (R) variant derived from one specific type into fully encapsulated and virulent (S) cells of a heterologous specific type. A typical instance will suffice to illustrate the techniques originally used and serve to indicate the wide variety of transformations that are possible within the limits of this bacterial species.

Griffith found that mice injected subcutaneously with a small amount of a living $\mathbf{R}$ culture derived from Pneumococcus Type II together with a large inoculum of heat-killed Type III (S) cells frequently succumbed to infection, and that the heart's blood of these animals yielded Type III pneumococci in pure culture. The fact that the $\mathbf{R}$ strain was avirulent and incapable by itself of causing fatal bacteremia and the additional fact that the heated suspension of Type III cells contained no viable organisms brought convincing evidence that the $\mathbf{R}$ forms growing under these conditions had newly acquired the capsular structure and biological specificity of Type III pneumococci.

The original observations of Griffith were later confirmed by Neufeld and Levinthal (2), and by Baurhenn (3) abroad, and by Dawson (4) in this laboratory. Subsequently Dawson and Sia (5) succeeded in inducing transformation in vitro. This they accomplished by growing $R$ cells in a fluid medium containing anti- $R$ serum and heat-killed encapsulated $S$ cells. They showed that in the test tube as in the animal body transformation can be selectively induced, depending on the type specificity of the $\mathrm{S}$ cells used in the reaction system. Later, Alloway (6) was able to cause

\footnotetext{
* Work done in part as Fellow in the Medical Sciences of the National Research Council.
} 
specific transformation in vitro using sterile extracts of $S$ cells from which all formed elements and cellular debris had been removed by Berkefeld filtration. He thus showed that crude extracts containing active transforming material in soluble form are as effective in inducing specific transformation as are the intact cells from which the extracts were prepared.

Another example of transformation which is analogous to the interconvertibility of pneumococcal types lies in the field of viruses. Berry and Dedrick (7) succeeded in changing the virus of rabbit fibroma (Shope) into that of infectious myxoma (Sanarelli). These investigators inoculated rabbits with a mixture of active fibroma virus together with a suspension of heat-inactivated myxoma virus and produced in the animals the symptoms and pathological lesions characteristic of infectious myxomatosis. On subsequent animal passage the transformed virus was transmissible and induced myxomatous infection typical of the naturally occurring disease. Later Berry (8) was successful in inducing the same transformation using a heat-inactivated suspension of washed elementary bodies of myxoma virus. In the case of these viruses the methods employed were similar in principle to those used by Griffith in the transformation of pneumococcal types. These observations have subsequently been confirmed by other investigators (9).

The present paper is concerned with a more detailed analysis of the phenomenon of transformation of specific types of Pneumococcus. The major interest has centered in attempts to isolate the active principle from crude bacterial extracts and to identify if possible its chemical nature or at least to characterize it sufficiently to place it in a general group of known chemical substances. For purposes of study, the typical example of transformation chosen as a working model was the one with which we have had most experience and which consequently seemed best suited for analysis. This particular example represents the transformation of a non-encapsulated $R$ variant of Pneumococcus Type II to Pneumococcus Type III.

\section{EXPERIMENTAL}

Transformation of pneumococcal types in vitro requires that certain cultural conditions be fulfilled before it is possible to demonstrate the reaction even in the presence of a potent extract. Not only must the broth medium be optimal for growth but it must be supplemented by the addition of serum or serous fluid known to possess certain special properties. Moreover, the $\mathbf{R}$ variant, as will be shown later, must be in the reactive phase in which it has the capacity to respond to the transforming stimulus. For purposes of convenience these several components as combined in the transforming test will be referred to as the reaction system. Each constituent of this system presented problems which required clarification before it was possible to obtain consistent and reproducible results. The various components of the system will be described in the following order: (1) nutrient broth, (2) serum or serous fluid, (3) strain of $R$ Pneumococcus, and (4) extraction, purification, and chemical nature of the transforming principle. 
OSWALD T. AVERY, COLIN M. MACLEOD, AND MACLYN MCCARTY

1. Nutrient Broth.-Beef heart infusion broth containing 1 per cent neopeptone with no added dextrose and adjusted to an initial $\mathrm{pH}$ of 7.6-7.8 is used as the basic medium. Individual lots of broth show marked and unpredictable variations in the property of supporting transformation. It has been found, however, that charcoal adsorption, according to the method described by MacLeod and Mirick (10) for removal of sulfonamide inhibitors, eliminates to a large extent these variations; consequently this procedure is used as routine in the preparation of consistently effective broth for titrating the transforming activity of extracts.

2. Serum or Serous Fluid.-In the first successful experiments on the induction of transformation in vitro, Dawson and Sia (5) found that it was essential to add serum to the medium. Anti-R pneumococcal rabbit serum was used because of the observation that reversion of an $R$ pneumococcus to the homologous $S$ form can be induced by growth in a medium containing anti-R serum. Alloway (6) later found that ascitic or chest fluid and normal swine serum, all of which contain $\mathbf{R}$ antibodies, are capable of replacing antipneumococcal rabbit serum in the reaction system. Some form of serum is essential, and to our knowledge transformation in vitro has never been effected in the absence of serum or serous fluid.

In the present study human pleural or ascitic fluid has been used almost exclusively. It became apparent, however, that the effectiveness of different lots of serum varied and that the differences observed were not necessarily dependent upon the content of $\mathbf{R}$ antibodies, since many sera of high titer were found to be incapable of supporting transformation. This fact suggested that factors other than $R$ antibodies are involved.

It has been found that sera from various animal species, irrespective of their immune properties, contain an enzyme capable of destroying the transforming principle in potent extracts. The nature of this enzyme and the specific substrate on which it acts will be referred to later in this paper. This enzyme is inactivated by heating the serum at $60^{\circ}-65^{\circ} \mathrm{C}$., and sera heated at temperatures known to destroy the enzyme are often rendered effective in the transforming system. Further analysis has shown that certain sera in which $R$ antibodies are present and in which the enzyme has been inactivated may nevertheless fail to support transformation. This fact suggests that still another factor in the serum is essential. The content of this factor varies in different sera, and at present its identity is unknown.

There are at present no criteria which can be used as a guide in the selection of suitable sera or serous fluids except that of actually testing their capacity to support transformation. Fortunately, the requisite properties are stable and remain unimpaired over long periods of time; and sera that have been stored in the refrigerator for many months have been found on retesting to have lost little or none of their original effectiveness in supporting transformation.

The recognition of these various factors in serum and their rôle in the reaction system has greatly facilitated the standardization of the cultural conditions required for obtaining consistent and reproducible results.

3. The $R$ Strain $(R 36 A)$. - The unencapsulated $R$ strain used in the present study was derived from a virulent " $S$ " culture of Pneumococcus Type II. It will be recalled that irrespective of type derivation all " $R$ " variants of Pneumococcus are characterized by the lack of capsule formation and the 
consequent loss of both type specificity and the capacity to produce infection in the animal body. The designation of these variants as $R$ forms has been used to refer merely to the fact that on artificial media the colony surface is "rough" in contrast to the smooth, glistening surface of colonies of encapsulated $\mathrm{S}$ cells.

The $R$ strain referred to above as $R 36 \mathrm{~A}$ was derived by growing the parent $\mathrm{S}$ culture of Pneumococcus Type II in broth containing Type II antipneumococcus rabbit serum for 36 serial passages and isolating the variant thus induced. The strain R36A has lost all the specific and distinguishing characteristics of the parent S organisms and consists only of attenuated and non-encapsulated $R$ variants. The change $S \rightarrow R$ is often a reversible one provided the $R$ cells are not too far "degraded." The reversion of the $R$ form to its original specific type can frequently be accomplished by successive animal passages or by repeated serial subculture in anti-R serum. When reversion occurs under these conditions, however, the $\mathbf{R}$ culture invariably reverts to the encapsulated form of the same specific type as that from which it was derived (11). Strain R36A has become relatively fixed in the $R$ phase and has never spontaneously reverted to the Type II S form. Moreover, repeated attempts to cause it to revert under the conditions just mentioned have in all instances been unsuccessful.

The reversible conversion of $S \rightleftharpoons R$ within the limits of a single type is quite different from the transformation of one specific type of Pneumococcus into another specific type through the $\mathbf{R}$ form. Transformation of types has never been observed to occur spontaneously and has been induced experimentally only by the special techniques outlined earlier in this paper. Under these conditions, the enzymatic synthesis of a chemically and immunologically different capsular polysaccharide is specifically oriented and selectively determined by the specific type of $S$ cells used as source of the transforming agent.

In the course of the present study it was noted that the stock culture of R36 on serial transfers in blood broth undergoes spontaneous dissociation giving rise to a number of other $\mathbf{R}$ variants which can be distinguished one from another by colony form. The significance of this in the present instance lies in the fact that of four different variants isolated from the parent $R$ culture only one ( $R 36 \mathrm{~A}$ ) is susceptible to the transforming action of potent extracts, while the others fail to respond and are wholly inactive in this regard. The fact that differences exist in the responsiveness of different $\mathbf{R}$ variants to the same specific stimulus enphasizes the care that must be exercised in the selection of a suitable $R$ variant for use in experiments on transformation. The capacity of this $R$ strain (R36A) to respond to a variety of different transforming agents is shown by the readiness with which it can be transformed to Types I, III, VI, or XIV, as well as to its original type (Type II), to which, as pointed out, it has never spontaneously reverted.

Although the significance of the following fact will become apparent later on, it must be mentioned here that pneumococcal cells possess an enzyme capable of destroying the activity of the transforming principle. Indeed, this enzyme has been 
OSWALD T. AVERY, COLIN M. MACLEOD, AND MACLYN MCCARTY

found to be present and highly active in the autolysates of a number of different strains. The fact that this intracellular enzyme is released during autolysis may explain, in part at least, the observation of Dawson and Sia (5) that it is essential in bringing about transformation in the test tube to use a small inoculum of young and actively growing $\mathbf{R}$ cells. The irregularity of the results and often the failure to induce transformation when large inocula are used may be attributable to the release from autolyzing cells of an amount of this enzyme sufficient to destroy the transforming principle in the reaction system.

In order to obtain consistent and reproducible results, two facts must be borne in mind: first, that an $\mathrm{R}$ culture can undergo spontaneous dissociation and give rise to other variants which have lost the capacity to respond to the transforming stimulus; and secondly, that pneumococcal cells contain an intracellular enzyme which when released destroys the activity of the transforming principle. Consequently, it is important to select a responsive strain and to prevent as far as possible the destructive changes associated with autolysis.

Method of Titration of Transforming Activity.-In the isolation and purification of the active principle from crude extracts of pneumococcal cells it is desirable to have a method for determining quantitatively the transforming activity of various fractions.

The experimental procedure used is as follows: Sterilization of the material to be tested for activity is accomplished by the use of alcohol since it has been found that this reagent has no effect on activity. A measured volume of extract is precipitated in a sterile centrifuge tube by the addition of 4 to 5 volumes of absolute ethyl alcohol, and the mixture is allowed to stand 8 or more hours in the refrigerator in order to effect sterilization. The alcohol precipitated material is centrifuged, the supernatant discarded, and the tube containing the precipitate is allowed to drain for a few minutes in the inverted position to remove excess alcohol. The mouth of the tube is then carefully flamed and a dry, sterile cotton plug is inserted. The precipitate is redissolved in the original volume of saline. Sterilization of active material by this technique has invariably proved effective. This procedure avoids the loss of active substance which may occur when the solution is passed through a Berkefeld filter or is heated at the high temperatures required for sterilization.

To the charcoal-adsorbed broth described above is added 10 per cent of the sterile ascitic or pleural fluid which has previously been heated at $60^{\circ} \mathrm{C}$. for 30 minutes, in order to destroy the enzyme known to inactivate the transforming principle. The enriched medium is distributed under aseptic conditions in $2.0 \mathrm{cc}$. amounts in sterile tubes measuring $15 \times 100 \mathrm{~mm}$. The sterilized extract is diluted serially in saline neutralized to $\mathrm{pH}$ 7.2-7.6 by addition of $0.1 \mathrm{~N} \mathrm{NaOH}$, or it may be similarly diluted in $\mathrm{M} / 40$ phosphate buffer, $\mathrm{pH} 7.4$. $0.2 \mathrm{cc}$. of each dilution is added to at least 3 or 4 tubes of the serum medium. The tubes are then seeded with a 5 to 8 hour blood broth culture of R36A. $0.05 \mathrm{cc}$. of a $10^{-4}$ dilution of this culture is added to each tube, and the cultures are incubated at $37^{\circ} \mathrm{C}$. for 18 to 24 hours. 
TRANSFORMATION OF PNEUMOCOCCAL TYPES

The anti- $R$ properties of the serum in the medium cause the $R$ cells to agglutinate during growth, and clumps of the agglutinated cells settle to the bottom of the tube leaving a clear supernatant. When transformation occurs, the encapsulated $\mathrm{S}$ cells, not being affected by these antibodies, grow diffusely throughout the medium. On the other hand, in the absence of transformation the supernatant remains clear, and only sedimented growth of $\mathbf{R}$ organisms occurs. This difference in the character of growth makes it possible by inspection alone to distinguish tentatively between positive and negative results. As routine all the cultures are plated on blood agar for confirmation and further bacteriological identification. Since the extracts used in the present study were derived from Pneumococcus Type III, the differentiation between the colonies of the original $\mathrm{R}$ organism and those of the transformed $\mathrm{S}$ cells is especially striking, the latter being large, glistening, mucoid colonies typical of Pneumococcus Type III. Figs. 1 and 2 illustrate these differences in colony form.

A typical protocol of a titration of the transforming activity of a highly purified preparation is given in Table IV.

\section{Preparative Methods}

Source Material.-In the present investigation a stock laboratory strain of Pneumococcus Type III (A66) has been used as source material for obtaining the active principle. Mass cultures of these organisms are grown in $\mathbf{5 0}$ to $\mathbf{7 5}$ liter lots of plain beef heart infusion broth. After 16 to 18 hours' incubation at $37^{\circ} \mathrm{C}$. the bacterial cells are collected in a steam-driven sterilizable Sharples centrifuge. The centrifuge is equipped with cooling coils immersed in ice water so that the culture fluid is thoroughly chilled before flowing into the machine. This procedure retards autolysis during the course of centrifugation. The sedimented bacteria are removed from the collecting cylinder and resuspended in approximately $150 \mathrm{cc}$. of chilled saline (0.85 per cent $\mathrm{NaCl}$ ), and care is taken that all clumps are thoroughly emulsified. The glass vessel containing the thick, creamy suspension of cells is immersed in a water bath, and the temperature of the suspension rapidly raised to $65^{\circ} \mathrm{C}$. During the heating process the material is constantly stirred, and the temperature maintained at $65^{\circ} \mathrm{C}$. for 30 minutes. Heating at this temperature inactivates the intracellular enzyme known to destroy the transforming principle.

Extraction of Heat-Killed Cells.-Although various procedures have been used, only that which has been found most satisfactory will be described here. The heatkilled cells are washed with saline 3 times. The chief value of the washing process is to remove a large excess of capsular polysaccharide together with much of the protein, ribonucleic acid, and somatic " $\mathrm{C}$ " polysaccharide. Quantitative titrations of transforming activity have shown that not more than 10 to 15 per cent of the active material is lost in the washing, a loss which is small in comparison to the amount of inert substances which are removed by this procedure.

After the final washing, the cells are extracted in $150 \mathrm{cc}$. of saline containing sodium desoxycholate in final concentration of 0.5 per cent by shaking the mixture me- 
OSWALD T. AVERY, COLIN M. MACLEOD, AND MACLYN MCCARTY

chanically 30 to 60 minutes. The cells are separated by centrifugation, and the extraction process is repeated 2 or 3 times. The desoxycholate extracts prepared in this manner are clear and colorless. These extracts are combined and precipitated by the addition of 3 to 4 volumes of absolute ethyl alcohol. The sodium desoxycholate being soluble in alcohol remains in the supernatant and is thus removed at this step. The precipitate forms a fibrous mass which floats to the surface of the alcohol and can be removed directly by lifting it out with a spatula. The excess alcohol is drained from the precipitate which is then redissolved in about $50 \mathrm{cc}$. of saline. The solution obtained is usually viscous, opalescent, and somewhat cloudy.

Deproteinization and Removal of Capsular Polysaccharide.-The solution is then deproteinized by the chloroform method described by Sevag (12). The procedure is repeated 2 or 3 times until the solution becomes clear. After this preliminary treatment the material is reprecipitated in 3 to 4 volumes of alcohol. The precipitate obtained is dissolved in a larger volume of saline (150 cc.) to which is added 3 to 5 mg. of a purified preparation of the bacterial enzyme capable of hydrolyzing the Type III capsular polysaccharide (13). The mixture is incubated at $37^{\circ} \mathrm{C}$., and the destruction of the capsular polysaccharide is determined by serological tests with Type III antibody solution prepared by dissociation of immune precipitate according to the method described by Liu and Wu (14). The advantages of using the antibody solution for this purpose are that it does not react with other serologically active substances in the extract and that it selectively detects the presence of the capsular polysaccharide in dilutions as high as 1:6,000,000. The enzymatic breakdown of the polysaccharide is usually complete within 4 to 6 hours, as evidenced by the loss of serological reactivity. The digest is then precipitated in 3 to 4 volumes of ethyl alcohol, and the precipitate is redissolved in $50 \mathrm{cc}$. of saline. Deproteinization by the chloroform process is again used to remove the added enzyme protein and remaining traces of pneumococcal protein. The procedure is repeated until no further film of protein-chloroform gel is visible at the interface.

Alcohol Fractionation.-Following deproteinization and enzymatic digestion of the capsular polysaccharide, the material is repeatedly fractionated in ethyl alcohol as follows. Absolute ethyl alcohol is added dropwise to the solution with constant stirring. At a critical concentration varying from 0.8 to 1.0 volume of alcohol the active material separates out in the form of fibrous strands that wind themselves around the stirring rod. This precipitate is removed on the rod and washed in a 50 per cent mixture of alcohol and saline. Although the bulk of active material is removed by fractionation at the critical concentration, a small but appreciable amount remains in solution. However, upon increasing the concentration of alcohol to 3 volumes, the residual fraction is thrown down together with inert material in the form of a flocculent precipitate. This flocculent precipitate is taken up in a small volume of saline (5 to $10 \mathrm{cc}$.) and the solution again fractionated by the addition of 0.8 to 1.0 volume of alcohol. Additional fibrous material is obtained which is combined with that recovered from the original solution. Alcoholic fractionation is repeated 4 to 5 times. The yield of fibrous material obtained by this method varies from 10 to 25 mg. per 75 liters of culture and represents the major portion of active material present in the original crude extract.

Effect of Temperature.-As a routine procedure all steps in purification were carried 


\section{TRANSFORMATION OF PNEUMOCOCCAL TYPES}

out at room temperature unless specifically stated otherwise. Because of the theoretical advantage of working at low temperature in the preparation of biologically active material, the purification of one lot (preparation 44) was carried out in the cold. In this instance all the above procedures with the exception of desoxycholate exextraction and enzyme treatment were conducted in a cold room maintained at $0-4^{\circ} \mathrm{C}$. This preparation proved to have significantly higher activity than did material similarly prepared at room temperature.

Desoxycholate extraction of the heat-killed cells at low temperature is less efficient and yields smaller amounts of the active fraction. It has been demonstrated that higher temperatures facilitate extraction of the active principle, although activity is best preserved at low temperatures.

\section{Analysis of Purified Transforming Material}

General Properties.-Saline solutions containing 0.5 to $1.0 \mathrm{mg}$. per cc. of the purified substance are colorless and clear in diffuse light. However, in strong transmitted light the solution is not entirely clear and when stirred exhibits a silky sheen. Solutions at these concentrations are highly viscous.

Purified material dissolved in physiological salt solution and stored at $2-4^{\circ} \mathrm{C}$. retains its activity in undiminished titer for at least 3 months. However, when dissolved in distilled water, it rapidly decreases in activity and becomes completely inert within a few days. Saline solutions stored in the frozen state in a $\mathrm{CO}_{2}$ ice box $\left(-70^{\circ} \mathrm{C}\right.$.) retain full potency for several months. Similarly, material precipitated from saline solution by alcohol and stored under the supernatant remains active over a long period of time. Partially purified material can be preserved by drying from the frozen state in the lyophile apparatus. However, when the same procedure is used for the preservation of the highly purified substance, it is found that the material undergoes changes resulting in decrease in solubility and loss of activity.

The activity of the transforming principle in crude extracts withstands heating for 30 to 60 minutes at $65^{\circ} \mathrm{C}$. Highly purified preparations of active material are less stable, and some loss of activity occurs at this temperature. A quantitative study of the effect of heating purified material at higher temperatures has not as yet been made. Alloway (6), using crude extracts prepared from Type III pneumococcal cells, found that occasionally activity could still be demonstrated after 10 minutes' exposure in the water bath to temperatures as high as $90^{\circ} \mathrm{C}$.

The procedures mentioned above were carried out with solutions adjusted to neutral reaction, since it has been shown that hydrogen ion concentrations in the acid range result in progressive loss of activity. Inactivation occurs rapidly at $\mathrm{pH} 5$ and below.

Qualitative Chemical Tests.-The purified material in concentrated solution gives negative biuret and Millon tests. These tests have been done directly on dry material with negative results. The Dische diphenylamine reaction 
OSWALD T. AVERY, COLIN M. MACLEOD, AND MACLYN MCCARTY

for desoxyribonucleic acid is strongly positive. The orcinol test (Bial) for ribonucleic acid is weakly positive. However, it has been found that in similar concentrations pure preparations of desoxyribonucleic acid of animal origin prepared by different methods give a Bial reaction of corresponding intensity.

Although no specific tests for the presence of lipid in the purified material have been made, it has been found that crude material can be repeatedly extracted with alcohol and ether at $-12^{\circ} \mathrm{C}$. without loss of activity. In addition, as will be noted in the preparative procedures, repeated alcohol precipitation and treatment with chloroform result in no decrease in biological activity.

Elementary Chemical Analysis. ${ }^{-}-$Four purified preparations were analyzed for content of nitrogen, phosphorus, carbon, and hydrogen. The results are presented in Table I. The nitrogen-phosphorus ratios vary from 1.58 to 1.75 with an average value of 1.67 which is in close agreement with that calculated

TABLE I

Elementary Chemical Analysis of Purified Preparations of the Transforming Substance

\begin{tabular}{c|c|c|c|c|c}
\hline Preparation No. & Carbon & Hydrogen & Nitrogen & Phosphorus & N/P ratio \\
\cline { 1 - 2 } \cline { 2 - 4 } per cent & per cent & per cent & per cent & \\
37 & 34.27 & 3.89 & 14.21 & 8.57 & 1.66 \\
42 & - & - & 15.93 & 9.09 & 1.75 \\
44 & 35.50 & 3.76 & 15.36 & 9.04 & 1.69 \\
\hline Theory for sodium & - & - & 13.40 & 8.45 & 1.58 \\
desoxyribonucleate.... & 34.20 & 3.21 & 15.32 & 9.05 & 1.69 \\
\hline
\end{tabular}

on the basis of the theoretical structure of sodium desoxyribonucleate (tetranucleotide). The analytical figures by themselves do not establish that the substance isolated is a pure chemical entity. However, on the basis of the nitrogen-phosphorus ratio, it would appear that little protein or other substances containing nitrogen or phosphorus are present as impurities since if they were this ratio would be considerably altered.

Enzymatic Analysis.-Various crude and crystalline enzymes ${ }^{2}$ have been tested for their capacity to destroy the biological activity of potent bacterial extracts. Extracts buffered at the optimal $\mathrm{pH}$, to which were added crystalline trypsin and chymotrypsin or combinations of both, suffered no loss in activity following treatment with these enzymes. Pepsin could not be tested because

1 The elementary chemical analyses were made by Dr. A. Elek of The Rockefeller Institute.

${ }^{2}$ The authors are indebted to Dr. John H. Northrop and Dr. M. Kunitz of The Rockefeller Institute for Medical Research, Princeton, N. J., for the samples of crystalline trypsin, chymotrypsin, and ribonuclease used in this work. 
TRANSFORMATION OF PNEUMOCOCCAL TYPES

extracts are rapidly inactivated at the low $\mathrm{pH}$ required for its use. Prolonged treatment with crystalline ribonuclease under optimal conditions caused no demonstrable decrease in transforming activity. The fact that trypsin, chymotrypsin, and ribonuclease had no effect on the transforming principle is further evidence that this substance is not ribonucleic acid or a protein susceptible to the action of tryptic enzymes.

In addition to the crystalline enzymes, sera and preparations of enzymes obtained from the organs of various animals were tested to determine their effect on transforming activity. Certain of these were found to be capable of completely destroying biological activity. The various enzyme preparations tested included highly active phosphatases obtained from rabbit bone by the method of Martland and Robison (15) and from swine kidney as described by

TABLE II

The Inactivation of Transforming Principle by Crude Enzyme Preparations

\begin{tabular}{|c|c|c|c|c|}
\hline \multirow[b]{2}{*}{ Crude enzyme preparations } & \multicolumn{4}{|c|}{ Enzymatic activity } \\
\hline & Phosphatase & $\begin{array}{c}\text { Tributyrin } \\
\text { esterase }\end{array}$ & $\begin{array}{l}\text { Depolymer- } \\
\text { ase for } \\
\text { desoxyribo- } \\
\text { nucleate }\end{array}$ & $\begin{array}{c}\text { Inactivation } \\
\text { of trans- } \\
\text { forming } \\
\text { principle }\end{array}$ \\
\hline Dog intestinal mucosa.... & + & + & + & + \\
\hline Rabbit bone phosphatase. . & + & + & - & - \\
\hline Swine kidney " & + & - & - & - \\
\hline Pneumococcus autolysates. & - & + & + & + \\
\hline Normal dog and rabbit serum. & + & + & + & + \\
\hline
\end{tabular}

H. and E. Albers (16). In addition, a preparation made from the intestinal mucosa of dogs by Levene and Dillon (17) and containing a polynucleotidase for thymus nucleic acid was used. Pneumococcal autolysates and a commercial preparation of pancreatin were also tested. The alkaline phosphatase activity of these preparations was determined by their action on $\beta$-glycerophosphate and phenyl phosphate, and the esterase activity by their capacity to split tributyrin. Since the highly purified transforming material isolated from pneumococcal extracts was found to contain desoxyribonucleic acid, these same enzymes were tested for depolymerase activity on known samples of desoxyribonucleic acid isolated by Mirsky ${ }^{3}$ from fish sperm and mammalian tissues. The results are summarized in Table II in which the phosphatase, esterase, and nucleodepolymerase activity of these enzymes is compared with their capacity to destroy the transforming principle. Analysis of these results shows that irrespective of the presence of phosphatase or esterase only those

${ }^{3}$ The authors express their thanks to Dr. A. E. Mirsky of the Hospital of The Rockefeller Institute for these preparations of desoxyribonucleic acid. 
OSWALD T. AVERY, COLIN M. MACLEOD, AND MACLYN MCCARTY

preparations shown to contain an enzyme capable of depolymerizing authentic samples of desoxyribonucleic acid were found to inactivate the transforming principle.

Greenstein and Jenrette (18) have shown that tissue extracts, as well as the milk and serum of several mammalian species, contain an enzyme system which causes depolymerization of desoxyribonucleic acid. To this enzyme system Greenstein has later given the name desoxyribonucleodepolymerase (19). These investigators determined depolymerase activity by following the reduction in viscosity of solutions of sodium desoxyribonucleate. The nucleate and enzyme were mixed in the viscosimeter and viscosity measurements made at intervals during incubation at $30^{\circ} \mathrm{C}$. In the present study this method was used in the measurement of depolymerase activity except that incubation was carried out at $37^{\circ} \mathrm{C}$. and, in addition to the reduction of viscosity, the action of the enzyme was further tested by the progressive decrease in acid precipitability of the nucleate during enzymatic breakdown.

The effect of fresh normal dog and rabbit serum on the activity of the transforming substance is shown in the following experiment.

Sera obtained from a normal dog and normal rabbit were diluted with an equal volume of physiological saline. The diluted serum was divided into three equal portions. One part was heated at $65^{\circ} \mathrm{C}$. for 30 minutes, another at $60^{\circ} \mathrm{C}$. for 30 minutes, and the third was used unheated as control. A partially purified preparation of transforming material which had previously been dried in the lyophile apparatus was dissolved in saline in a concentration of $3.7 \mathrm{mg}$. per cc. $1.0 \mathrm{cc}$. of this solution was mixed with $0.5 \mathrm{cc}$. of the various samples of heated and unheated diluted sera, and the mixtures at $\mathrm{pH} 7.4$ were incubated at $37^{\circ} \mathrm{C}$. for 2 hours. After the serum had been allowed to act on the transforming material for this period, all tubes were heated at $65^{\circ} \mathrm{C}$. for 30 minutes to stop enzymatic action. Serial dilutions were then made in saline and tested in triplicate for transforming activity according to the procedure described under Method of titration. The results given in Table III illustrate the differential heat inactivation of the enzymes in dog and rabbit serum which destroy the transforming principle.

From the data presented in Table III it is evident that both dog and rabbit serum in the unheated state are capable of completely destroying transforming activity. On the other hand, when samples of dog serum which have been heated either at $60^{\circ} \mathrm{C}$. or at $65^{\circ} \mathrm{C}$. for 30 minutes are used, there is no loss of transforming activity. Thus, in this species the serum enzyme responsible for destruction of the transforming principle is completely inactivated at $60^{\circ} \mathrm{C}$. In contrast to these results, exposure to $65^{\circ} \mathrm{C}$. for 30 minutes was required for complete destruction of the corresponding enzyme in rabbit serum.

The same samples of dog and rabbit serum used in the preceding experiment were also tested for their depolymerase activity on a preparation of sodium desoxyribonucleate isolated by Mirsky from shad sperm. 
TRANSFORMATION OF PNEUMOCOCCAL TYPES

A highly viscous solution of the nucleate in distilled water in a concentration of 1 mg. per cc. was used. $1.0 \mathrm{cc}$. amounts of heated and unheated sera diluted in saline as shown in the preceding protocol were mixed in Ostwald viscosimeters with $4.0 \mathrm{cc}$.

TABLE III

Differential Beat Inactivation of Enzymes in Dog and Rabbit Serum Which Destroy the Transforming Substance

\begin{tabular}{|c|c|c|c|c|c|c|c|c|}
\hline & \multirow{3}{*}{$\begin{array}{l}\text { Heat treatment } \\
\text { of serum }\end{array}$} & \multirow{3}{*}{ Dilution* } & \multicolumn{6}{|c|}{ Triplicate tests } \\
\hline & & & \multicolumn{2}{|r|}{1} & \multicolumn{2}{|r|}{2} & \multicolumn{2}{|r|}{3} \\
\hline & & & 总害 & $\begin{array}{l}\text { Colony } \\
\text { form }\end{array}$ & 总要 & $\begin{array}{l}\text { Colony } \\
\text { form }\end{array}$ & 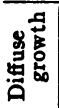 & $\begin{array}{c}\text { Colony } \\
\text { form }\end{array}$ \\
\hline \multirow{3}{*}{ Dog serum } & Unheated & $\begin{array}{c}\text { Undiluted } \\
1: 5 \\
1: 25\end{array}$ & $\begin{array}{l}- \\
- \\
-\end{array}$ & $\begin{array}{l}\text { R only } \\
\mathrm{R} \text { “ } \\
\mathrm{R}\end{array}$ & $\begin{array}{l}- \\
- \\
-\end{array}$ & $\begin{array}{l}\mathrm{R} \text { only } \\
\mathrm{R} \\
\mathrm{R}\end{array}$ & $\begin{array}{l}- \\
- \\
-\end{array}$ & $\begin{array}{l}\mathrm{R} \text { only } \\
\mathrm{R} \text { “ } \\
\mathrm{R} \text { “ }\end{array}$ \\
\hline & $\begin{array}{l}60^{\circ} \mathrm{C} \text {. for } 30 \\
\text { min. }\end{array}$ & $\begin{array}{c}\text { Undiluted } \\
1: 5 \\
1: 25\end{array}$ & $\begin{array}{l}+ \\
+ \\
+\end{array}$ & $\begin{array}{l}\text { SIII } \\
\text { SIII } \\
\text { SIII }\end{array}$ & $\begin{array}{l}+ \\
+ \\
+\end{array}$ & $\begin{array}{l}\text { SIII } \\
\text { SIII } \\
\text { SIII }\end{array}$ & $\begin{array}{l}+ \\
+ \\
+\end{array}$ & $\begin{array}{l}\text { SIII } \\
\text { SIII } \\
\text { SIII }\end{array}$ \\
\hline & $\begin{array}{l}65^{\circ} \mathrm{C} \text {. for } 30 \\
\text { min. }\end{array}$ & $\begin{array}{c}\text { Undiluted } \\
1: 5 \\
1: 25\end{array}$ & $\begin{array}{l}+ \\
+ \\
+\end{array}$ & $\begin{array}{l}\text { SIII } \\
\text { SIII } \\
\text { SIII }\end{array}$ & $\begin{array}{l}+ \\
+ \\
+\end{array}$ & $\begin{array}{l}\text { SIII } \\
\text { SIII } \\
\text { SIII }\end{array}$ & $\begin{array}{l}+ \\
+ \\
+\end{array}$ & $\begin{array}{l}\text { SIII } \\
\text { SIII } \\
\text { SIII }\end{array}$ \\
\hline \multirow{3}{*}{ Rabbit serum } & Unheated & $\begin{array}{c}\text { Undiluted } \\
1: 5 \\
1: 25\end{array}$ & $\begin{array}{l}- \\
-\end{array}$ & $\begin{array}{l}\mathbf{R} \text { only } \\
\mathbf{R} \text { “ } \\
\mathbf{R} \text { “ }\end{array}$ & $\begin{array}{l}- \\
-\end{array}$ & $\begin{array}{l}\mathrm{R} \text { only } \\
\mathrm{R} \text { “ } \\
\mathrm{R}\end{array}$ & $\begin{array}{l}- \\
- \\
-\end{array}$ & $\begin{array}{l}\mathrm{R} \text { only } \\
\mathrm{R} \text { “" } \\
\mathrm{R}\end{array}$ \\
\hline & $\begin{array}{l}60^{\circ} \mathrm{C} \text {. for } 30 \\
\text { min. }\end{array}$ & $\begin{array}{c}\text { Undiluted } \\
1: 5 \\
1: 25\end{array}$ & $\begin{array}{l}- \\
- \\
-\end{array}$ & $\begin{array}{l}\text { R only } \\
\text { R “ } \\
\mathrm{R} \text { “ }\end{array}$ & $\begin{array}{l}- \\
- \\
-\end{array}$ & $\begin{array}{l}\mathrm{R} \text { only } \\
\mathrm{R} \text { “" } \\
\mathrm{R} \text { “ }\end{array}$ & $\begin{array}{l}- \\
- \\
-\end{array}$ & $\begin{array}{l}R \text { only } \\
R \text { “" } \\
R \text { “" }\end{array}$ \\
\hline & $\begin{array}{l}65^{\circ} \mathrm{C} \text {. for } 30 \\
\text { min. }\end{array}$ & $\begin{array}{c}\text { Undiluted } \\
1: 5 \\
1: 25\end{array}$ & $\begin{array}{l}+ \\
+ \\
+\end{array}$ & $\begin{array}{l}\text { SIII } \\
\text { SIII } \\
\text { SIII }\end{array}$ & $\begin{array}{l}+ \\
+ \\
+\end{array}$ & $\begin{array}{l}\text { SIII } \\
\text { SIII } \\
\text { SIII }\end{array}$ & $\begin{array}{l}+ \\
+ \\
+\end{array}$ & $\begin{array}{l}\text { SIII } \\
\text { SIII } \\
\text { SIII }\end{array}$ \\
\hline $\begin{array}{c}\text { Control (no } \\
\text { serum) }\end{array}$ & None & $\begin{array}{c}\text { Undiluted } \\
1: 5 \\
1: 25\end{array}$ & $\begin{array}{l}+ \\
+ \\
+\end{array}$ & $\begin{array}{l}\text { SIII } \\
\text { SIII } \\
\text { SIII }\end{array}$ & $\begin{array}{l}+ \\
+ \\
+\end{array}$ & $\begin{array}{l}\text { SIII } \\
\text { SIII } \\
\text { SIII }\end{array}$ & $\begin{array}{l}+ \\
+ \\
+\end{array}$ & $\begin{array}{l}\text { SIII } \\
\text { SIII } \\
\text { SIII }\end{array}$ \\
\hline
\end{tabular}

* Dilution of the digest mixture of serum and transforming substance.

of the aqueous solution of the nucleate. Determinations of viscosity were made immediately and at intervals over a period of 24 hours during incubation at $37^{\circ} \mathrm{C}$.

The results of this experiment are graphically presented in Chart 1 . In the case of unheated serum of both dog and rabbit, the viscosity fell to that of water in 5 to 7 hours. Dog serum heated at $60^{\circ} \mathrm{C}$. for 30 minutes brought about 
OSWALD T. AVERY, COLIN M. MACLEOD, AND MACLYN MCCARTY

no significant reduction in viscosity after 22 hours. On the other hand, heating rabbit serum at $60^{\circ} \mathrm{C}$. merely reduced the rate of depolymerase action, and after 24 hours the viscosity was brought to the same level as with the unheated serum. Heating at $65^{\circ} \mathrm{C}$., however, completely destoyed the rabbit serum depolymerase.

Thus, in the case of dog and rabbit sera there is a striking parallelism between the temperature of inactivation of the depolymerase and that of the enzyme which destroys the activity of the transforming principle. The fact that this difference in temperature of inactivation is not merely a general property of all enzymes in the sera is evident from experiments on the heat inactivation of

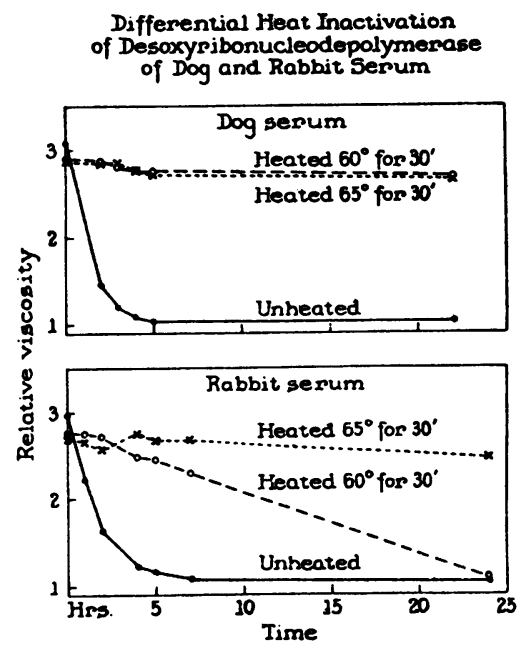

Chart 1

tributyrin esterase in the same samples of serum. In the latter instance, the results are the reverse of those observed with depolymerase since the esterase of rabbit serum is almost completely inactivated at $60^{\circ} \mathrm{C}$. while that in $\operatorname{dog}$ serum is only slightly affected by exposure to this temperature.

Of a number of substances tested for their capacity to inhibit the action of the enzyme known to destroy the transforming principle, only sodium fluoride has been found to have a significant inhibitory effect. Regardless of whether this enzyme is derived from pneumococcal cells, dog intestinal mucosa, pancreatin, or normal sera its activity is inhibited by fluoride. Similarly it has been found that fluoride in the same concentration also inhibits the enzymatic depolymerization of desoxyribonucleic acid.

The fact that transforming activity is destroyed only by those preparations containing depolymerase for desoxyribonucleic acid and the further fact that 
in both instances the enzymes concerned are inactivated at the same temperature and inhibited by fluoride provide additional evidence for the belief that the active principle is a nucleic acid of the desoxyribose type.

Serological Analysis. - In the course of chemical isolation of the active material it was found that as crude extracts were purified, their serological activity in Type III antiserum progressively decreased without corresponding loss in biological activity. Solutions of the highly purified substance itself gave only faint trace reactions in precipitin tests with high titer Type III antipneumococcus rabbit serum. ${ }^{4}$ It is well known that pneumococcal protein can be detected by serological methods in dilutions as high as 1:50,000 and the capsular as well as the somatic polysaccharide in dilutions of at least 1:5,000,000. In view of these facts, the loss of serological reactivity indicates that these cell constituents have been almost completely removed from the final preparations. The fact that the transforming substance in purified state exhibits little or no serological reactivity is in striking contrast to its biological specificity in inducing pneumococcal transformation.

Physicochemical Studies. ${ }^{5}-$ A purified and active preparation of the transforming substance (preparation 44) was examined in the analytical ultracentrigue. The material gave a single and unusually sharp boundary indicating that the substance was homogeneous and that the molecules were uniform in size and very asymmetric. Biological activity was found to be sedimented at the same rate as the optically observed boundary, showing that activity could not be due to the presence of an entity much different in size. The molecular weight cannot be accurately determined until measurements of the diffusion constant and partial specific volume have been made. However, Tennent and Vilbrandt (20) have determined the diffusion constant of several preparations of thymus nucleic acid the sedimentation rate of which is in close agreement with the values observed in the present study. Assuming that the asymmetry of the molecules is the same in both instances, it is estimated that the molecular weight of the pneumococcal preparation is of the order of 500,000 .

Examination of the same active preparation was carried out by electrophoresis in the Tiselius apparatus and revealed only a single electrophoretic component of relatively high mobility comparable to that of a nucleic acid. Transforming activity was associated with the fast moving component giving the

1 The Type III antipneumococcus rabbit serum employed in this study was furnished through the courtesy of Dr. Jules T. Freund, Bureau of Laboratories, Department of Health, City of New York.

${ }^{6}$ Studies on sedimentation in the ultracentrifuge were carried out by Dr. A. Rothen; the electrophoretic analyses were made by Dr. T. Shedlovsky, and the ultraviolet absorption curves by Dr. G. I. Lavin. The authors gratefully acknowledge their indebtedness to these members of the staff of The Rockefeller Institute. 
OSWALD T. AVERY, COLIN M. MACLEOD, AND MACLYN MCCARTY

optically visible boundary. Thus in both the electrical and centrifugal fields, the behavior of the purified substance is consistent with the concept that biological activity is a property of the highly polymerized nucleic acid.

Ultraviolet absorption curves showed maxima in the region of $2600 \AA$ and minima in the region of $2350 \AA$. These findings are characteristic of nucleic acids.

Quantitative Determination of Biological Activity.-In its highly purified state the material as isolated has been found to be capable of inducing transformation in amounts ranging from 0.02 to $0.003 \mu \mathrm{g}$. Preparation 44, the purification of which was carried out at low temperature and which had a nitrogen-phosphorus

TABLE IV

Titration of Transforming Activity of Preparation 44

\begin{tabular}{|c|c|c|c|c|c|c|c|c|c|}
\hline \multirow{2}{*}{\multicolumn{2}{|c|}{$\begin{array}{l}\text { Transforming principle } \\
\text { Preparation 44: }\end{array}$}} & \multicolumn{8}{|c|}{ Quadruplicate tests } \\
\hline & & \multicolumn{2}{|c|}{1} & \multicolumn{2}{|c|}{2} & \multicolumn{2}{|c|}{3} & \multicolumn{2}{|c|}{4} \\
\hline Dilution & $\begin{array}{c}\text { Amount } \\
\text { added }\end{array}$ & $\begin{array}{l}\text { Diffuse } \\
\text { growth }\end{array}$ & $\begin{array}{l}\text { Colony } \\
\text { form }\end{array}$ & $\begin{array}{l}\text { Diffuse } \\
\text { growth }\end{array}$ & $\begin{array}{l}\text { Colony } \\
\text { form }\end{array}$ & $\begin{array}{l}\text { Diffuse } \\
\text { growth }\end{array}$ & $\begin{array}{c}\text { Colony } \\
\text { form }\end{array}$ & $\begin{array}{l}\text { Diffuse } \\
\text { growth }\end{array}$ & $\begin{array}{c}\text { Colony } \\
\text { form }\end{array}$ \\
\hline $10^{-2}$ & $\begin{array}{l}\mu \mathrm{g} . \\
1.0\end{array}$ & + & SIII & + & SIII & + & SIII & + & SIII \\
\hline $10^{-2.5}$ & 0.3 & + & SIII & + & SIII & + & SIII & + & SIII \\
\hline $10^{-3}$ & 0.1 & + & SIII & + & SIII & + & SIII & $t$ & SIII \\
\hline $10^{-3.5}$ & 0.03 & + & SIII & + & SIII & + & SIII & + & SIII \\
\hline $10^{-4}$ & 0.01 & + & SIII & + & SIII & + & SIII & + & SIII \\
\hline $10^{-4.5}$ & 0.003 & - & R only & + & SIII & - & R only & + & SIII \\
\hline $10^{-5}$ & 0.001 & - & R “ & - & R only & - & R “ & - & $\mathbf{R}$ only \\
\hline Control & None & - & R “ & - & R “ & - & R “ & - & R “ \\
\hline
\end{tabular}

* Solution from which dilutions were made contained $0.5 \mathrm{mg}$. per cc. of purified material. $0.2 \mathrm{cc}$. of each dilution added to quadruplicate tubes containing $2.0 \mathrm{cc}$. of standard serum broth. $0.05 \mathrm{cc}$. of a $10^{-4}$ dilution of a blood broth culture of R36A is added to each tube.

ratio of 1.58 , exhibited high transforming activity. Titration of the activity of this preparation is given in Table IV.

A solution containing $0.5 \mathrm{mg}$. per cc. was serially diluted as shown in the protocol. $0.2 \mathrm{cc}$. of each of these dilutions was added to quadruplicate tubes containing $2.0 \mathrm{cc}$. of standard serum broth. All tubes were then inoculated with $0.05 \mathrm{cc}$. of a $10^{-4}$ dilution of a 5 to 8 hour blood broth culture of R36A. Transforming activity was determined by the procedure described under Method of titration.

The data presented in Table IV show that on the basis of dry weight 0.003 $\mu \mathrm{g}$. of the active material brought about transformation. Since the reaction system containing the $0.003 \mu \mathrm{g}$. has a volume of $2.25 \mathrm{cc}$., this represents a final concentration of the purified substance of 1 part in $600,000,000$. 


\section{DISCUSSION}

The present study deals with the results of an attempt to determine the chemical nature of the substance inducing specific transformation of pneumococcal types. A desoxyribonucleic acid fraction has been isolated from Type III pneumococci which is capable of transforming unencapsulated $R$ variants derived from Pneumococcus Type II into fully encapsulated Type III cells. Thompson and Dubos (21) have isolated from pneumococci a nucleic acid of the ribose type. So far as the writers are aware, however, a nucleic acid of the desoxyribose type has not heretofore been recovered from pneumococci nor has specific transformation been experimentally induced in vitro by a chemically defined substance.

Although the observations are limited to a single example, they acquire broader significance from the work of earlier investigators who demonstrated the interconvertibility of various pneumococcal types and showed that the specificity of the changes induced is in each instance determined by the particular type of encapsulated cells used to evoke the reaction. From the point of view of the phenomenon in general, therefore, it is of special interest that in the example studied, highly purified and protein-free material consisting largely, if not exclusively, of desoxyribonucleic acid is capable of stimulating unencapsulated R variants of Pneumococcus Type II to produce a capsular polysaccharide identical in type specificity with that of the cells from which the inducing substance was isolated. Equally striking is the fact that the substance evoking the reaction and the capsular substance produced in response to it are chemically distinct, each belonging to a wholly different class of chemical compounds.

The inducing substance, on the basis of its chemical and physical properties, appears to be a highly polymerized and viscous form of sodium desoxyribonucleate. On the other hand, the Type III capsular substance, the synthesis of which is evoked by this transforming agent, consists chiefly of a non-nitrogenous polysaccharide constituted of glucose-glucuronic acid units linked in glycosidic union (22). The presence of the newly formed capsule containing this type-specific polysaccharide confers on the transformed cells all the distinguishing characteristics of Pneumococcus Type III. Thus, it is evident that the inducing substance and the substance produced in turn are chemically distinct and biologically specific in their action and that both are requisite in determining the type specificity of the cell of which they form a part.

The experimental data presented in this paper strongly suggest that nucleic acids, at least those of the desoxyribose type, possess different specificities as evidenced by the selective action of the transforming principle. Indeed, the possibility of the existence of specific differences in biological behavior of nucleic acids has previously been suggested $(23,24)$ but has never been experimentally demonstrated owing in part at least to the lack of suitable biological methods. 
OSWALD T. AVERY, COLIN M. MACLEOD, AND MACLYN MCCARTY

The techniques used in the study of transformation appear to afford a sensitive means of testing the validity of this hypothesis, and the results thus far obtained add supporting evidence in favor of this point of view.

If it is ultimately proved beyond reasonable doubt that the transforming activity of the material described is actually an inherent property of the nucleic acid, one must still account on a chemical basis for the biological specificity of its action. At first glance, immunological methods would appear to offer the ideal means of determining the differential specificity of this group of biologically important substances. Although the constituent units and general pattern of the nucleic acid molecule have been defined, there is as yet relatively little known of the possible effect that subtle differences in molecular configuration may exert on the biological specificity of these substances. However, since nucleic acids free or combined with histones or protamines are not known to function antigenically, one would not anticipate that such differences would be revealed by immunological techniques. Consequently, it is perhaps not surprising that highly purified and protein-free preparations of desoxyribonucleic acid, although extremely active in inducing transformation, showed only faint trace reactions in precipitin tests with potent Type III antipneumococcus rabbit sera.

From these limited observations it would be unwise to draw any conclusion concerning the immunological significance of the nucleic acids until further knowledge on this phase of the problem is available. Recent observations by Lackman and his collaborators (25) have shown that nucleic acids of both the yeast and thymus type derived from hemolytic streptococci and from animal and plant sources precipitate with certain antipneumococcal sera. The reactions varied with different lots of immune serum and occurred more frequently in antipneumococcal horse serum than in corresponding sera of immune rabbits. The irregularity and broad cross reactions encountered led these investigators to express some doubt as to the immunological significance of the results. Unless special immunochemical methods can be devised similar to those so successfully used in demonstrating the serological specificity of simple non-antigenic substances, it appears that the techniques employed in the study of transformation are the only ones available at present for testing possible differences in the biological behavior of nucleic acids.

Admittedly there are many phases of the problem of transformation that require further study and many questions that remain unanswered largely because of technical difficulties. For example, it would be of interest to know the relation between rate of reaction and concentration of the transforming substance; the proportion of cells transformed to those that remain unaffected in the reaction system. However, from a bacteriological point of view, numerical estimations based on colony counts might prove more misleading than enlightening because of the aggregation and sedimentation of the $R$ cells ag- 
TRANSFORMATION OF PNEUMOCOCCAL TYPES

glutinated by the antiserum in the medium. Attempts to induce transformation in suspensions of resting cells held under conditions inhibiting growth and multiplication have thus far proved unsuccessful, and it seems probable that transformation occurs only during active reproduction of the cells. Important in this connection is the fact that the $\mathrm{R}$ cells, as well as those that have undergone transformation, presumably also all other variants and types of pneumococci, contain an intracellular enzyme which is released during autolysis and in the free state is capable of rapidly and completely destroying the activity of the transforming agent. It would appear, therefore, that during the logarithmic phase of growth when cell division is most active and autolysis least apparent, the cultural conditions are optimal for the maintenance of the balance between maximal reactivity of the $\mathrm{R}$ cell and minimal destruction of the transforming agent through the release of autolytic ferments.

In the present state of knowledge any interpretation of the mechanism involved in transformation must of necessity be purely theoretical. The biochemical events underlying the phenomenon suggest that the transforming principle interacts with the $R$ cell giving rise to a coordinated series of enzymatic reactions that culminate in the synthesis of the Type III capsular antigen. The experimental findings have clearly demonstrated that the induced alterations are not random changes but are predictable, always corresponding in type specificity to that of the encapsulated cells from which the transforming substance was isolated. Once transformation has occurred, the newly acquired characteristics are thereafter transmitted in series through innumerable transfers in artificial media without any further addition of the transforming agent. Moreover, from the transformed cells themselves, a substance of identical activity can again be recovered in amounts far in excess of that originally added to induce the change. It is evident, therefore, that not only is the capsular material reproduced in successive generations but that the primary factor, which controls the occurrence and specificity of capsular development, is also reduplicated in the daughter cells. The induced changes are not temporary modifications but are permanent alterations which persist provided the cultural conditions are favorable for the maintenance of capsule formation. The transformed cells can be readily distinguished from the parent $R$ forms not alone by serological reactions but by the presence of a newly formed and visible capsule which is the immunological unit of type specificity and the accessory structure essential in determining the infective capacity of the microorganism in the animal body.

It is particularly significant in the case of pneumococci that the experimentally induced alterations are definitely correlated with the development of a new morphological structure and the consequent acquisition of new antigenic and invasive properties. Equally if not more significant is the fact that these changes are predictable, type-specific, and heritable. 
OSWALD T. AVERY, COLIN M. MACLEOD, AND MACLYN MCCARTY

Various hypotheses have been advanced in explanation of the nature of the changes induced. In his original description of the phenomenon Griffith (1) suggested that the dead bacteria in the inoculum might furnish some specific protein that serves as a "pabulum" and enables the $\mathrm{R}$ form to manufacture a capsular carbohydrate.

More recently the phenomenon has been interpreted from a genetic point of view $(26,27)$. The inducing substance has been likened to a gene, and the capsular antigen which is produced in response to it has been regarded as a gene product. In discussing the phenomenon of transformation Dobzhansky (27) has stated that "If this transformation is described as a genetic mutation-and it is difficult to avoid so describing it-we are dealing with authentic cases of induction of specific mutations by specific treatments...."

Another interpretation of the phenomenon has been suggested by Stanley (28) who has drawn the analogy between the activity of the transforming agent and that of a virus. On the other hand, Murphy (29) has compared the causative agents of fowl tumors with the transforming principle of Pneumococcus. He has suggested that both these groups of agents be termed "transmissible mutagens" in order to differentiate them from the virus group. Whatever may prove to be the correct interpretation, these differences in viewpoint indicate the implications of the phenomenon of transformation in relation to similar problems in the fields of genetics, virology, and cancer research.

It is, of course, possible that the biological activity of the substance described is not an inherent property of the nucleic acid but is due to minute amounts of some other substance adsorbed to it or so intimately associated with it as to escape detection. If, however, the biologically active substance isolated in highly purified form as the sodium salt of desoxyribonucleic acid actually proves to be the transforming principle, as the available evidence strongly suggests, then nucleic acids of this type must be regarded not merely as structurally important but as functionally active in determining the biochemical activities and specific characteristics of pneumococcal cells. Assuming that the sodium desoxyribonucleate and the active principle are one and the same substance, then the transformation described represents a change that is chemically induced and specifically directed by a known chemical compound. If the results of the present study on the chemical nature of the transforming principle are confirmed, then nucleic acids must be regarded as possessing biological specificity the chemical basis of which is as yet undetermined.

\section{SUMMARY}

1. From Type III pneumococci a biologically active fraction has been isolated in highly purified form which in exceedingly minute amounts is capable under appropriate cultural conditions of inducing the transformation of unencapsulated $R$ variants of Pneumococcus Type II into fully encapsulated cells of the 
TRANSFORMATION OF PNEUMOCOCCAL TYPES

same specific type as that of the heat-killed microorganisms from which the inducing material was recovered.

2. Methods for the isolation and purification of the active transforming material are described.

3. The data obtained by chemical, enzymatic, and serological analyses together with the results of preliminary studies by electrophoresis, ultracentrifugation, and ultraviolet spectroscopy indicate that, within the limits of the methods, the active fraction contains no demonstrable protein, unbound lipid, or serologically reactive polysaccharide and consists principally, if not solely, of a highly polymerized, viscous form of desoxyribonucleic acid.

4. Evidence is presented that the chemically induced alterations in cellular structure and function are predictable, type-specific, and transmissible in series. The various hypotheses that have been advanced concerning the nature of these changes are reviewed.

\section{CONCLUSION}

The evidence presented supports the belief that a nucleic acid of the desoxyribose type is the fundamental unit of the transforming principle of Pneumococcus Type III.

\section{BIBLIOGRAPHY}

1. Griffith, F., J. Hyg., Cambridge, Eng., 1928, 27, 113.

2. Neufeld, F., and Levinthal, W., Z. Immunitätsforsch., 1928, 55, 324.

3. Baurhenn, W., Centr. Bakt., 1. Abt., Orig., 1932, 126, 68.

4. Dawson, M. H., J. Exp. Med., 1930, 51, 123.

5. Dawson, M. H., and Sia, R. H. P., J. Exp. Med., 1931, 54, 681.

6. Alloway, J. L., J. Exp. Med., 1932, 55, 91; 1933, 67, 265.

7. Berry, G. P., and Dedrick, H. M., J. Bact., 1936, 31, 50.

8. Berry, G. P., Arch. Path., 1937, 24, 533.

9. Hurst, E. W., Brit. J. Exp. Path., 1937, 18, 23. Hoffstadt, R. E., and Pilcher, K. S., J. Infect. Dis., 1941, 68, 67. Gardner, R. E., and Hyde, R. R., J. Infect. Dis., 1942, 71, 47. Houlihan, R. B., Proc. Soc. Exp. Biol. and Med., 1942, 51, 259.

10. MacLeod, C. M., and Mirick, G. S., J. Bact., 1942, 44, 277.

11. Dawson, M. H., J. Exp. Med., 1928, 47, 577; 1930, 51, 99.

12. Sevag, M. G., Biochem. Z., 1934, 273, 419. Sevag, M. G., Lackman, D. B., and Smolens, J., J. Biol. Chem., 1938, 124, 425.

13. Dubos, R. J., and Avery, O. T., J. Exp. Med., 1931, 54, 51. Dubos, R. J., and Bauer, J. H., J. Exp. Med., 1935, 62, 271.

14. Liu, S., and Wu, H., Chinese J. Physiol., 1938, 13, 449.

15. Martland, M., and Robison, R., Biochem. J., 1929, $23,237$.

16. Albers, H., and Albers, E., Z. physiol. Chem., 1935, $232,189$.

17. Levene, P. A., and Dillon, R. T., J. Biol. Chem., 1933, 96, 461.

18. Greenstein, J. P., and Jenrette, W. Y., J. Nat. Cancer Inst., 1940, 1, 845. 
OSWALD T. AVERY, COLIN M. MACLEOD, AND MACLYN MCCARTY

19. Greenstein, J. P., J. Nat. Cancer Inst., 1943, 4, 55.

20. Tennent, H. G., and Vilbrandt, C. F., J. Am. Chem. Soc., 1943, 65, 424.

21. Thompson, R. H. S., and Dubos, R. J., J. Biol. Chem., 1938, 125, 65.

22. Reeves, R. E., and Goebel, W. F., J. Biol. Chem., 1941, 139, 511.

23. Schultz, J., in Genes and chromosomes. Structure and organization, Cold Spring Harbor symposia on quantitative biology, Cold Spring Harbor, Long Island Biological Association, 1941, 9, 55.

24. Mirsky, A. E., in Advances in enzymology and related subjects of biochemistry, (F. F. Nord and C. H. Werkman, editors), New York, Interscience Publishers, Inc., 1943, 3, 1.

25. Lackman, D., Mudd, S., Sevag, M. G., Smolens, J., and Wiener, M., J. Immunol., $1941,40,1$.

26. Gortner, R. A., Outlines of biochemistry, New York, Wiley, 2nd edition, 1938, 547.

27. Dobzhansky, T., Genetics and the origin of the species, New York, Columbia University Press, 1941, 47.

28. Stanley, W. M., in Doerr, R., and Hallauer, C., Handbuch der Virusforschung, Vienna, Julius Springer, 1938, 1, 491.

29. Murphy, J. B., Tr. Assn. Am. Physn., 1931, 46, 182; Bull. Johns Bopkins Hosp., $1935,66,1$. 
TRANSFORMATION OF PNEUMOCOCCAL TYPES

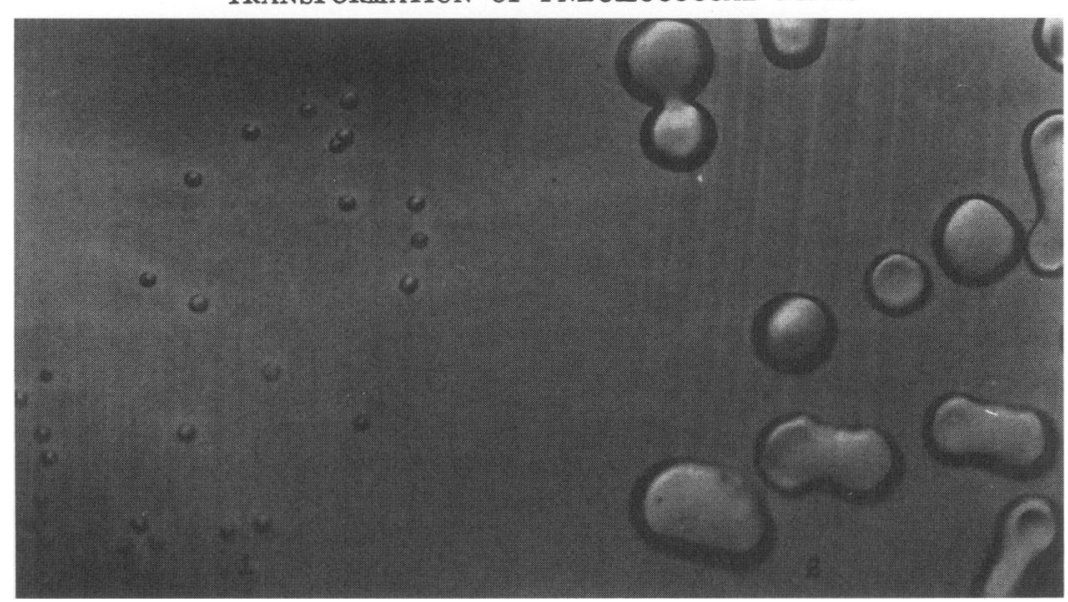

EXPLANATION OF PLATE 1

The photograph was made by Mr. Joseph B. Haulenbeek.

FIG. 1. Colonies of the $R$ variant (R36A) derived from Pneumococcus Type II. Plated on blood agar from a culture grown in serum broth in the absence of the transforming substance. $\times 3.5$.

Fig. 2. Colonies on blood agar of the same cells after induction of transformation during growth in the same medium with the addition of active transforming principle isolated from Type III pneumococci. The smooth, glistening, mucoid colonies shown are characteristic of Pneumococcus Type III and readily distinguishable from the small, rough colonies of the parent $\mathbf{R}$ strain illustrated in Fig. 1 . $\times 3.5$. 